\title{
SATISFAÇÃO COM A VIDA EM IDOSOS: PREVALENCIA E DETERMINANTES
}

\author{
Rosa Martins* \\ Preciosa Santos $^{\dagger}$ \\ Ana Andrade
}

Resumo: Nos últimos anos, tem-se verificado uma preocupação social em manter os idosos em casa, surgindo assim o serviço de apoio domiciliário numa tentativa de evitar a institucionalização. Este serviço vai tentar agir em conjunto com a família (quando esta existe), para que os idosos não se sintam como um estorvo mas sim felizes e satisfeitos com a vida. A satisfação com a vida é um construto que corresponde a um desejo em qualquer fase da vida, incluindo na velhice, sendo influenciado por diversas variáveis pessoais, sociais e psicológicas.

Objetivos: Identificar a satisfação com a vida em Idosos com apoio Domiciliário e sua relação com variáveis sociodemográficas e psicossociais.

Métodos: O modelo de investigação adoptado, é do tipo quantitativo, não experimental, descritivo, correlacional, retrospetivo e transversal. Participaram no estudo 66 idosos. $O$ instrumento de colheita de dados utilizado integra as secções: Fatores pessoais, Fatores situacionais, Escala de Avaliação da Funcionalidade Familiar, escala de Investimento na vida Pessoal e a Escala para Medida da Satisfação com a Vida.

Resultados: A população estudada é maioritariamente feminina, com idades superiores a 70 anos e predominante casada. São pessoas pouco alfabetizadas ( $4^{a}$ classe mais comum), reformadas por limite de idade, possuindo parcos recursos económicos. Beneficiam do serviço de apoio domiciliário em média entre 1 a 8 horas semanais, e a perceção que têm sobre as ajudas em situação de emergência, doença elou financeiras é muito positiva. A maioria perceciona ainda famílias com moderada disfunção e entendem ter tido um investimento pessoal entre moderado/elevado. A maioria dos Idosos

\footnotetext{
* Professora Coordenadora da Escola Superior de Saúde, do Instituto Politécnico de Viseu. E-mail: rmartins.viseu@gmail.com

$\dagger$ Psicóloga Clinica em Leiria

* Professora Adjunta da Escola Superior de Saúde, do Instituto Politécnico de Viseu
} 
está pouco ou moderadamente satisfeita com a vida, porém não se obtiveram correlações estatísticas significativas entre esta e as variáveis sociodemográficas e psicossociais.

Palavras-chave: Idosos, Apoio domiciliário, Funcionalidade familiar, Satisfação com a Vida.

\title{
Title: SATISFACTION WITH LIFE IN ELDERLY: PREVALENCE AND ITS FACTORS
}

\begin{abstract}
Background: Over the last few years, there has been a rising concern towards keeping elder people in their own homes instead of sending them to private institutions giving rise to home support services. The aim of this service is to act with the subject's family (when present) in order to prevent him from falling apart from society and from feeling joy for living. Feeling joy for living is to which one relates at any given phase of his life, even through the old age. The joy for living is influenced by several components such as personal, social and psychological.

Objectives: To identify the satisfaction levels towards life in the case of elder people with home support services and in what way it relates to socio-demographic and psychosocial variables.

Methods: The investigation approach used is of the quantitative type, non-experimental, descriptive, correlative, retrospective and transversal. 66 elder people took part as subjects for this study. The gathering of data integrates the following sections: Personal factors, Situational factors, Family functionality scale evaluation and the Life satisfaction scale.

Results: The most of the subjects for this study are above 70 years old married women. They don't have nearly much studies, are retired due to old age and have limited financial resources. They benefit from home support services for between one to eight hours per week and their perception of the response to emergency, disease or financial situations is very positive. Most of the subjects find their family to be moderately dysfunctional and to have had a moderate or high level of engagement towards them. That most elder people are unsatisfied or moderately satisfied with their life in general, however, no statistic correlation was established between this last result and the sociodemographic and psychosocial variables.
\end{abstract}

Key words: elderly, home support services, familiar functionality, satisfaction with life. 


\section{INTRODUÇÃO}

O envelhecimento demográfico que se tem verificado nos últimos tempos, impele-nos a uma reflexão acerca das alterações estruturais, funcionais e sociais que comporta. $\mathrm{O}$ aumento da esperança média de vida da população idosa pode associar-se a maiores níveis de incapacidade funcional aos vários níveis, envolvendo o apoio de terceiros para satisfação das AVD, e com fortes implicações na satisfação com a vida.

A par das alterações estruturais e funcionais, também a pessoa idosa deixa muitas vezes de exercer a sua autonomia deixando de ser o "líder" não só da família, mas também da vida social e económica e passa a enfrentar problemas ao nível da relação familiar, social, de habitação e até de ocupação (Martins, 2008). Simultaneamente a redução do núcleo familiar, a sua dispersão e/ou, algumas vezes, a sua inexistência, conduzem a pessoa idosa a situações graves de isolamento e consequentemente institucionalização.

Assistimos a um fenómeno, que segundo Imaginário, (2004) tem fortes implicações sociais, exigindo o desenvolvimento de estratégias de apoio que vão de encontro à população idosa e às famílias. De facto, é necessário refletir sobre os aspetos relativos à idade de reforma, meios de subsistência, qualidade de vida, estatuto da pessoa idosa na sociedade, solidariedade intergeracional e sustentabilidade dos sistemas de segurança social e de saúde (INE, 2009), tendo sempre em consideração que a família continua a assumir uma importante posição no suporte social.

Corroboramos da tese de Teixeira, (2010), quando afirma “ que é absolutamente necessário adotar medidas que proporcionem uma velhice aos cidadãos com mais qualidade. Neste sentido, parece-nos de enorme utilidade a realização de pesquisas sobre diferentes aspetos do envelhecimento de forma a dar respostas reais e adaptadas as necessidades das pessoas de mais idade, no sentido de aumentarmos o apoio que esperam aumentando assim a sua satisfação com a vida.

As redes de suporte social têm aqui um papel fundamental, pois como conclui Erbolato (2004, cit. por Teixeira, 2010) num estudo que tinha por objetivo estudar a composição das redes sociais de idosos e a presença de suporte social e psicológico nas mesmas, as redes sociais revelam-se muito eficazes na manutenção da qualidade de vida dos Idosos, proporcionando oportunidades de comunicação, confidência, sentimentos de segurança e apoio. 
Sabemos hoje, através das evidências científicas, que são os desajustes familiares que conduzem o idoso ao internamento e consequente isolamento. Prevalece também a ideia, de que institucionalizar o idoso é abandoná-lo, e por isso a sua entrada nos lares será para muitos a última opção. Por outro lado, os lares promovem a imagem da incapacidade familiar, razão pela qual se recorre aos Serviços de Apoio Domiciliário, dado possibilitarem ao idoso a permanência no seu ambiente familiar, onde poderá, dentro das suas possibilidades, rentabilizar o controlo da sua vida (Stone, 2001 cit. por Martins e Carvalho, 2008). Neste sentido tornase necessário estimular a família, para que esta tome consciência da sua responsabilidade para com os mais velhos e reconheça, o papel importante que estes mesmos Idosos têm na coesão social e familiar. As redes sociais de apoio, mais não são do que formas como as ligações humanas se estruturam como sistemas de apoio (para manutenção e promoção da saúde das pessoas) e os recursos que são partilhados entre os membros desse sistema (Paúl, 2005) O papel protector das forças sociais sobre o homem e a sua influência no bem estar e satisfação com a vida são hoje indiscutíveis. As redes sociais de apoio à pessoa idosa dividem-se em dois grandes grupos: as redes de apoio informal e as redes de apoio formal. Nas primeiras, estão incluídas as famílias, vizinhos e amigos; nas segundas, incluem-se serviços estatais, de segurança social e os organizados pelo poder local (Lares para a Terceira Idade, Serviços de Apoio Domiciliário, Centros de Dia, etc...).

Em termos jurídico-normativos os Serviços de Apoio Domiciliário, (SAD) são definidos como uma “... resposta social que consiste na prestação de cuidados individualizados e personalizados no domicílio a indivíduos e famílias quando, por motivo de doença, deficiência ou outro impedimento, não possam assegurar, temporária ou permanentemente, a satisfação das necessidades básicas e/ou as atividades da vida diária." (Despacho Normativo n ${ }^{\circ} 62 / 99$, de 12 de Novembro).

São muitas as vantagens apontadas aos SAD como serviços, mas enfatiza-se sobretudo a proximidade com o sujeito, o conhecimento das necessidades reais no seu contexto familiar, o que torna esta resposta mais humanizada e com consequentes níveis mais elevados de satisfação.

A satisfação com a vida é um construto que corresponde a um desejo em qualquer fase da vida, incluindo na velhice, sendo influenciado por diversas variáveis pessoais, sociais e psicológicas. Numa perspetiva de envelhecimento ao longo da vida, onde a qualidade de vida assume uma importância vital, a satisfação e o bem-estar psicológico estão associados ao envelhecimento bem-sucedido (Sequeira, 2010). 
Na opinião de Alves (2008) o envelhecimento bem-sucedido, com satisfação de vida pode ser visto como uma competência adaptativa, ou seja, uma capacidade generalizada para responder com resiliência aos obstáculos impostos. Corroboramos Joia (2007), quando afirma que a satisfação com a vida é um fenómeno, por vezes difícil de mensurar, por se tratar de um estado revestido de grande subjetividade.

Enquanto subjetiva a avaliação da satisfação com a vida reflete as expressões de cada pessoa, quanto aos seus próprios critérios de satisfação com a vida, como um todo e em domínios específicos; reflete por exemplo o bem-estar individual, ou seja, o modo e os motivos que levam as pessoas a viverem as suas experiências de vida de maneira positiva. Tonarelli (2010), descreve a satisfação com a vida dos idosos como um sentimento de felicidade, contentamento e preenchimento, que as pessoas experimentam quando conseguem adaptar-se de forma satisfatória às alterações provocadas pelo envelhecimento. Segundo esta autora, a satisfação com a vida é a chave para o envelhecimento bemsucedido e reflete a qualidade de vida dessas pessoas. Dentro das determinantes que concorrem para a satisfação com a vida Martins (2006) destaca o apoio social, uma vez que exerce um efeito direto sobre o bem-estar, fomentando a saúde independentemente do nível de stress, o que significa que quanto maior for o apoio social menor será o mal-estar psicológico experimentado e consequente satisfação com a vida.

Um outro estudo da autoria de Resende (2006), mostrou que os idosos que apresentam uma rede social formada por familiares e amigos tendem a ter menos dificuldade em lidar com os eventos de vida stressantes, em virtude da ajuda dada ou recebida contribuir para o aumento do sentido de controlo pessoal, com influência positiva no bem-estar psicológico. $\mathrm{O}$ mesmo estudo revelou que a qualidade dos relacionamentos é mais importante na determinação da satisfação com a vida que a quantidade dos mesmos.

Partilhamos o sentir de Cruz (2010) ao referir, que os fatores que se apresentam como preditores dos níveis de satisfação com a vida nos idosos, não reúnem consensos, resultando deste facto contradições várias entre autores. Porém e apesar destas dissonâncias, são cinco as variáveis mais frequentemente empregues na sua predição: destacam-se assim as variáveis sociodemográficas, os relacionamentos sociais, a personalidade, o coping e a autoestima. Também Oliveira (2010) refere, que existe muita literatura sobre os fatores mais influentes no bem-estar subjectivo do idoso, contudo, a falta de consenso prevalece quer quanto ao peso de determinantes sociodemográficas (sexo, idade, cultura, estatuto económico-social, família, religião, etc.) quer quanto aos fatores de 
ordem pessoal (idiossincrasia, saúde física ou psíquica, atividades). Não obstante, destaca três fatores, essencialmente ligados á área pessoal, que em sua opinião são determinantes para uma velhice bem-sucedida: a saúde, a manutenção de um elevado nível de funcionamento cognitivo e físico e a manutenção da participação social, mesmo no período pós reforma.

As conclusões dum outro estudo, da autoria de Resende (2006), demonstram que os idosos que possuem uma rede social formada por familiares e amigos, tendem a ter menos dificuldades em lidar com os eventos de vida stressantes, uma vez que a ajuda dada ou recebida contribui para o aumento do sentido de controlo pessoal, com influência positiva no bem-estar psicológico. O mesmo estudo revelou, que a qualidade dos relacionamentos exerce maior peso na determinação da satisfação com a vida que a quantidade dos mesmos.

Independentemente dos níveis de satisfação com a vida verificados ao longo do envelhecimento, vários estudos mostram níveis elevados de satisfação em adultos com idades próximas dos 65 anos, mesmo tendo em consideração a deterioração da saúde e a presença de outras perdas ( Neri (2001); Silva (2009); Tonarelli (2010)).

\section{MATERIAL E MÉTODOS}

A metodologia consiste em descrever de forma sistemática a estrutura e as etapas de uma pesquisa. Segundo Fortin (2009), a metodologia da investigação pressupõe ao mesmo tempo um processo racional e um conjunto de técnicas ou de meios que permitam realizar a investigação.

Assim, e tendo em conta o anteriormente referido, faremos uma descrição da metodologia utilizada, que inclui as seguintes etapas: tipo de estudo, questões de investigação, objectivos, população em estudo, instrumento de colheita de dados e tratamento estatístico.

Trata-se de um estudo quantitativo, do tipo não experimenta, transversal, descritivo-correlacional na medida em que se pretende determinar se duas variáveis estão relacionadas e, simultaneamente, precisar a grandeza dessa relação através de análises estatísticas de correlação.

A questão de investigação é um enunciado interrogativo, claro e não equívoco que precisa os conceitos-chave, específica a natureza da população que se quer estudar e sugere investigação empírica. Assim, as questões de investigação que este estudo pretende explorar são: (1) "será que os idosos que recebem apoio domiciliário estão satisfeitos com a vida? (2) "em que medida a satisfação com a vida destes idosos se correlaciona com as variáveis sociodemográficas, funcionalidade familiar 
e investimento pessoal?". Os objectivos decorrentes das questões enunciadas, consistem em identificar níveis de satisfação com a vida no grupo de Idosos e em que medida esta é influenciada pelas variáveis sociodemográficas, pela funcionalidade familiar e pelo investimento pessoal percecionados.

A população alvo deste estudo, corresponde ao conjunto de idosos residentes no seu domicílio assistidos pelo SAD do concelho de Ourém. Optámos por uma amostra do tipo não probabilístico por conveniência, constituída por 66 Idosos, sendo 40 do sexo feminino e 26 do sexo masculino. A idade da amostra total, oscila entre um valor mínimo de 65 e um máximo de 95 anos, correspondendo-lhe uma idade média de 76,94 anos e um desvio padrão de 9,35 .

Os critérios de inclusão dos participantes para o nosso estudo foram: possuir idade igual ou superior a 65 anos; beneficiar dos serviços de apoio domiciliário e possuir capacidade cognitiva para colaborar na colheita de dados.

A nível de procedimentos, foi dirigido ofício com pedido de autorização para a aplicação do instrumento de colheita de dados (ICD) à Santa Casa de Misericórdia de Fátima-Ourém, onde era referenciado o responsável pela pesquisa, explicitados os objetivos e finalidade do estudo. Para além, do pedido formal à instituição foi apresentado a todos os idosos o documento de consentimento informado, a garantia de anonimato e confidencialidade dos dados recolhidos e ainda a liberdade de em qualquer altura poderem desistir se assim o desejassem.

A escolha dos métodos de colheita de dados depende das variáveis estudadas, da sua operacionalização, das questões de investigação/ hipóteses e do desenho do estudo delineado (FORTIN, 2009). No nosso caso optámos pela utilização de um questionário por nós construído e pela aplicação de escalas elaboradas por outros investigadores e consequentemente, já traduzidas e testadas na população portuguesa. $\mathrm{O}$ instrumento de colheita de dados (ICD) deste estudo, é composto por uma secção de caracterização sociodemográfica dos idosos; uma Escala de Apgar Familiar (EAF) de Smilkstein (1978), validada para a população portuguesa por Agostinho e Rebelo (1988); uma escala de Investimento na Vida Pessoal (EIVP) de Freire SA, e a Escala de medida da Satisfação com a Vida (ESV) de Dienner et al (1985), validada para a população portuguesa por Simões (1992).

O tratamento estatístico da presente investigação foi efectuado através do programa Statiscal Package Social Science versão 19.0 para o Windows e Word Microsoft. 


\section{RESULTADOS}

Esta secção do artigo, pretende apresentar discutir e interpretar os resultados, não só tendo em conta o significado de que se revestem neste contexto específico e regional, mas também à luz de outras fontes estudadas.

Assim, a amostra deste estudo é constituída por 66 idosos (40 do sexo feminino e 26 do sexo masculino), que vivem nos seus domicílios, beneficiando contudo de serviços de apoio domiciliário.

Os dados sociodemográficos caracterizadores da amostra, revelam diferenças na repartição por sexos, já que $60,4 \%$ dos idosos são do sexo feminino e apenas $39,4 \%$ do sexo masculino. Estes resultados comprovam os dados obtidos no último Recenseamento da população portuguesa em 2011, onde as mulheres predominavam comparativamente aos homens. Os fatores que tem sido apontados e que contribuem para esta tendência estão relacionados com a relação de masculinidade, os efeitos de sobremortalidade masculina e da esperança de vida, que como se sabe é sempre mais elevada no caso das mulheres.

A idade oscila entre um valor mínimo de 65 anos e um máximo de 95 correspondendo uma idade média de 76,94 anos, um fato que não nos surpreende tendo em conta o aumento da esperança média de vida à nascença. "Quanto ao aumento da esperança média de vida à nascença, esta situa-se nos 75,6 anos para os homens e 82,1 anos para as mulheres." (INE, 2009 cit. por Cerqueira, 2010)

Considerando o estado civil, verifica-se que a frequência de casado é superior na nossa amostra $(36,4 \%)$ seguindo-se os solteiros $(30,3 \%)$ e os viúvos $(18,2 \%)$. De realçar o número de divorciados neste grupo populacional $15,2 \%$, e ainda o predomínio de $21,2 \%$ mulheres solteiras. De facto estes dados vem confirmar a ideia de que ao longo dos anos o divórcio na população portuguesa tem adquirido uma maior visibilidade.

O estudo de Fernandes (2008) concluiu, que Portugal é dos países europeus que apresenta uma maior percentagem de inquiridos com os níveis mais baixos de escolaridade ( $12.8 \%$ não concluíram o $1^{\circ}$ ciclo do ensino básico, em contraste com a média europeia de 3\%; 46\% têm apenas o $1^{\circ}$ e o $2^{\circ}$ ciclo do ensino básico, em contraste com a média europeia de 9\%). Também no presente estudo se constata que os níveis de escolaridade são baixos, pois em maior destaque estão os indivíduos que têm menos de quatro anos de escolaridade (30,3\%), seguindo-se a quarta classe com $27,3 \%$ e com um valor próximo deste $(18,2)$ aqueles que possuem formação entre os quatro e seis anos. De facto em termos de 
habilitações académicas existem algumas diferenças por género, uma vez que, as mulheres, que constituem o maior valor percentual da nossa amostra, possuem níveis inferiores ao quarto ano de escolaridade. Diznos Antunes (2010), que o nível de instrução da população idosa em Portugal é deveras muito baixa uma vez que "a maioria dos idosos não possui qualquer nível de instrução, sendo esta característica mais acentuada nas mulheres idosas".

A nível profissional verifica-se que a maioria de idosos da nossa amostra se encontra reformada, pois apenas um elemento refere estar ainda a trabalhar. Percebe-se também que grande parte da amostra exerce essencialmente tarefas domésticas $(36,0 \%)$ o que não nos surpreende, uma vez que a amostra é fundamentalmente feminina e estas funções continuam, como diz Martins (2008), a pertencer maioritariamente às mulheres. Além disso seguiram-se com $15,6 \%$ as atividades agrícolas e com valor muito semelhante, atividades administrativas e comércio: são atividades que estão em conformidade com as características socioculturais dos participantes e com a região geográfica onde o estudo foi realizado, (Fátima- local de culto religioso) e onde as atividades decorrentes do intenso turismo, possibilita outas oportunidades (comércio e atividades administrativas).

A situação económica da maioria $(60,6 \%)$ dos idosos inquiridos reflete a ideia que estes se encontram em grande número no limiar da pobreza, porque dispõem mensalmente de rendimentos que se situam entre os $250 €$ e os $500 €$ havendo um grupo significativo $(21,2 \%)$ com valores inferiores a $250 €$, o que indica não terem disponibilidade económica para satisfazerem as suas necessidades básicas e viver condignamente. Estas condições são agravadas em muitos casos, devido aos gastos adicionais relativos à saúde uma vez que se trata de um grupo com idade média elevada (76,94 anos). Corroboramos Martins (2008) quando afirma que os baixos valores das pensões auferidas pelos idosos, prende-se por um lado à conjuntura social em que nos encontramos, e por outro, devido ás parcas e curtas carreiras contributivas.

As pensões constituem a componente mais importante dos rendimentos dos idosos, por isso cerca de $60,6 \%$ dos inquiridos tem uma pensão de reforma que deriva do limite de idade, ou seja, do regime contributivo. Não há margem de dúvida que as respostas sociais organizadas são já diversificadas, contudo, a população idosa tem crescido imenso ao longo dos últimos anos, o que faz com que estas respostas sociais poderão não conseguir acompanhar e satisfazer os idosos (Martins, 2006). 
A distância entre "os nossos idosos e os cuidadores" é pequena uma vez que para $(48,5 \%)$ dos mesmos os familiares vivem na mesma localidade e $(33,3 \%)$ vivem até na mesma casa. Com $9,1 \%$ temos os que dizem ter familiares a uma distância superior a $30 \mathrm{~km}$ e com o mesmo valor destacam-se aqueles que têm filhos emigrados. Como refere Fernandes (2008) o idoso são ou doente, (onde frequentemente existe acometimento de alguns órgãos e que acabam por levar o idoso a um grau de dependência), necessita de sentir apoio familiar pois em qualquer das circunstâncias este é de suma importância. A proximidade é um fator facilitador deste acompanhamento e pelo contrário as grandes distâncias propiciam afastamentos por vezes involuntários mas com efeitos nefastos na autoestima dos mais velhos.

Corroboramos os dados expressos no relatório da Santa Casa da Misericórdia de Mortágua Norte, (2011) quando referem que o aumento de pessoas mais velhas vulneráveis associado a um número pequeno de familiares que possam assegurar os cuidados necessários e a tentativa da não institucionalização, leva a uma necessidade crescente de desenvolvimento do serviço de Apoio Domiciliário, de forma a que as pessoas, cada vez mais, tenham a possibilidade de escolher esta resposta social, permitindo-lhe a satisfação das suas necessidades obtendo assim uma melhor qualidade de vida, permanecendo na sua habitação no meio das suas coisas que fazem parte de uma vida. A análise em função do género revela que as mulheres têm os cuidadores mais próximos que os homens.

Relativamente ao período de tempo em que auferem do apoio domiciliário, verificou-se que $42,4 \%$ dos idosos o recebem entre 3 a 5 anos, que $21,2 \%$ usufrui do mesmo entre 1 a 2 anos, e $27,3 \%$ há menos de 1 ano. De realçar que apenas 9,1 beneficiam deste serviço por um período superior a 5 anos. Estes dados confirmam a novidade desta resposta social pois como nos diz a AMI “... o projeto de Apoio Domiciliário tem uma história recente e tem um duplo objetivo pois, para além de fornecer um serviço domiciliário, é ao mesmo tempo uma empresa de inserção social. Também Capucha, (2005) refere nas conclusões do estudo que realizou, que o apoio domiciliário, apenas disponibiliza respostas para cerca de 38.000 idosos $(6,84 \%$ dos que têm mais de 75 anos), e apesar de ser uma solução tecnicamente preferível ao lar ou residência, quer do ponto de vista de qualidade de vida dos idosos que não são totalmente dependentes, quer ao nível dos custos, é porém menos praticada, em parte por outro tipo de soluções inovadoras, como prestação de serviços por parte de vizinhos devidamente treinados, escolhidos pelos próprios idosos e enquadrados pelo serviços públicos de 
ação social, são obstruídos pela pressão das instituições civis que dominam este setor.

Quanto ao número de horas de serviços que lhes são prestados vimos o seguinte: a grande maioria dos inquiridos $87,9 \%$, revelam um número que oscila entre 1 as 8 horas semanais, $9,1 \%$ recebe apoio que vai desde 9 horas a 20 horas e apenas um elemento do sexo masculino diz receber, 21 a 40 horas semanais. Estas informações corroboram a "escassez das respostas como um elemento bastante penalizante para uma grande parte dos idosos que se vão sentindo simultâneo, e cumulativamente mais isolados e menos capazes de desempenhar autonomamente e com segurança, atividades quotidianas, mais ou menos, elementares."( Gonçalves, 2004)

A perceção que os idosos têm sobre ajudas em situação de emergência ou doença são elevadas uma vez que $87,9 \%$ dos idosos sente que efetivamente será apoiado em caso de necessidade. Contudo existe um pequeno grupo $12,1 \%$ cujos sentimentos são de desamparo. Paralelamente um numero significativo de idosos ( $21,2 \%)$ não sabem a quem recorrer em caso de necessidades financeiras. Estes resultados mostram a heterogeneidade que prevalece na população idosa do nosso Pais uma vez que para alguns as redes de apoio social e familiar resolvem substancialmente todos os problemas enquanto outros continuam "esquecidos social e familiarmente vivendo em muitas situações no limiar da pobreza". Apesar de tudo e considerando as respostas da maioria "Os idosos utilizam as suas redes sociais - familiares e amigos, basicamente tanto para a resolução de problemas como para manter a sua integração na sociedade" (Osório, 2007 p. 232 cit. por Fernandes, 2010).

De acordo com os resultados obtidos através da Escala Funcionalidade Familiar e focando a nossa atenção na distribuição dos idosos pelos três níveis funcionais do APGAR Familiar, verificamos que as percentagens mais elevadas nos três grupos estão associadas a famílias moderadamente funcionais $54,5 \%$, seguindo-se as altamente funcionais $36,4 \%$ e por fim aquelas que acham ter disfunções acentuadas $9,1 \%$. De realçar, e de alguma forma surpreendente, que quando foram colhidos estes dados, os olhares, opiniões e comentários expressos casualmente, eram o oposto da resposta escolhida, como se tivessem "vergonha" de dizer que tinham problemas familiares, querendo de alguma forma dar uma boa imagem da interação familiar. Na verdade o modo singular como cada família reage aos eventos diários e fomenta o seu desenvolvimento, caracteriza a funcionalidade dessa mesma família. Também as diversas características sociais e psicológicas dos membros da família estabelecem os aspetos que definem a sua funcionalidade. De facto não existem modos de 
funcionamento familiar corretos ou errados, existem sim, formas de funcionalidade distintas que derivam da conjugação de três aspetos: as crenças e valores da família, os padrões de interação familiar e as competências da família. Para Santos e Pavarini (2011), existem diversos sistemas familiares: uns maduros e/ou funcionais, e outros imaturos e/ou disfuncionais. No entanto para Andrade e Martins (2011) o modo como os elementos da família interagem entre si e com os outros e o modo como cada um o sente, é que determina e prediz a funcionalidade ou a disfuncionalidade familiar.

Relativamente ao Investimento feito na Vida Pessoal, observámos que $39,4 \%$ dos idosos perceciona o seu investimento como elevado, 33,3\% entende-o como pequeno e um grupo mais pequeno $23,3 \%$ acha que o investimento foi moderado. Existem algumas diferenças no fator género, uma vez que, os homens tendem a avaliar o investimento de uma forma mais positiva (moderado/elevado), enquanto as mulheres incidem essencialmente no item correspondente ao pequeno investimento. Estas constatações vão na linha de pensamento de Melo (2009), quando refere, que por muito tempo permaneceu a noção de que a realização natural da mulher estaria no envolvimento afetivo e na procriação. Hoje em dia essa posição é claramente criticada, sendo inegável que essas motivações e atitudes são aprendidas desde muito cedo e moldadas segundo os estereótipos aceites por cada cultura. Também Sequeira (2010) refere que o idoso deve valorizar as suas necessidades, objetivos, anseios, hábitos e crenças, pois assim, vai sentir-se amado e compreendido, desenvolverá uma maior motivação para superar as dificuldades financeiras, físicas, emocionais e cognitivas. Acrescenta que por outro lado, criará alternativas que lhe possibilitem manifestar sua capacidade de atualização para manutenção de sua vida.

Os dados resultantes da aplicação da escala de satisfação com a vida demonstraram, que $36,3 \%$ dos idosos se encontra muito satisfeita com a vida, $45,5 \%$ pouco satisfeita e $18,2 \%$ moderadamente satisfeita. Apesar de um número significativo de participantes relatar estar satisfeito com a vida como demonstrámos, não podemos esquecer que 45,5\% (maior valor percentual) está insatisfeita. De fato o papel das redes sociais (que este grupo possui) e das relações sociais significativas no decurso do envelhecimento pode ter um efeito protetor e conservador da saúde (física e mental) dos idosos, mas que não abrange o universo estudado. Por outro lado a presença destas redes de apoio é fundamental para garantir a autonomia dos idosos, um autoconceito positivo e uma maior satisfação de vida, fundamentais para alcançar um envelhecimento bem-sucedido Paúl (2005). 
Mas a satisfação com a vida é um julgamento cognitivo de alguns domínios específicos da vida, como a saúde, o trabalho, as condições de habitação, as relações sociais, a autonomia, entre outros, ou seja, um processo de juízo e avaliação geral da própria vida de acordo com critérios próprios. Por outras palavras, o julgamento da satisfação depende de uma comparação entre as circunstâncias de vida do indivíduo e um padrão por ele estabelecido e por isso a disparidade de resultados do estudo.

Pretendíamos ainda compreender quais os fatores que contribuem para uma maior satisfação com a vida nos nossos idosos: os resultados mostraram a não existência de relações estatísticas significativas entre as variáveis sociodemográficas e a satisfação com a vida, contrariamente ao que esperávamos. No entanto um estudo levado a cabo por Martins (2008) concluiu que o facto dos idosos terem menos idade, serem sujeitos divorciados e/ou casados, serem do sexo feminino, possuírem níveis médios/superiores de instrução, e melhores condições económicas eram fatores que influenciavam positivamente a sua qualidade de vida e consequentemente contribuíam para a existência de indivíduos mais satisfeitos.

\section{CONCLUSÕES}

Os programas e políticas de envelhecimento ativo tão aclamado no ano de 2012, reconhecem a necessidade emergente de incentivar e equilibrar a responsabilidade pessoal, ou os investimentos de cada um para garantir um futuro melhor para si mesmo. Neste sentido é preciso que as pessoas (coletiva e individualmente) planeiem e se preparem para a velhice, esforçando-se e adotando hábitos saudáveis em todas as fases da vida.

Partilhamos dos pressupostos de Kalache (cit. por Martins 2006) quando explica que a noção de curso de vida é importante justamente para garantir que, desde cedo, as pessoas comecem a fazer os investimentos que vão fazer toda a diferença no futuro, garantindo desse modo as reservas de saúde, finanças e motivação para continuar vivendo. De igual modo os investimentos na interação familiar e nas redes de suporte e apoio são de importância fulcral na satisfação percebida.

Na opinião de Neri (2001), a satisfação com a vida reflete o nível percecionado da qualidade de vida que se tem e depende do nível de envolvimento de vários fatores, como os hábitos de vida, de atividade física, da perceção de bem-estar, das condições físicas e ambientais, do relacionamento familiar e da amizade. Este estudo reforçou a tese de que 
a satisfação com a vida corresponde a um sentimento de felicidade, contentamento e preenchimento, que as pessoas idosas experimentam quando conseguem adaptar-se de forma satisfatória às alterações provocadas pelo envelhecimento.

Neste sentido, pensamos ser de elevada pertinência o conhecimento real do contexto de vida em que os nossos idosos se desenvolvem, de modo a que a promoção das políticas e medidas instituídas e fomentadas possam ir ao encontro de uma vida com qualidade. As principais conclusões deste estudo mostram que:

A população estudada é maioritariamente feminina, com idade média 77 anos, são predominantemente casados e solteiros. São pessoas, pouco letradas, encontram-se reformados por limite de idade e alguns por invalidez. Possuem recursos económicos que os colocam no limiar da pobreza (entre 250 a $500 €$ por mês), mas residem a grande proximidade dos cuidadores sobretudo os indivíduos do sexo masculino.

O apoio domiciliário auferido por $42,4 \%$ dos idosos oscila entre os 3 e 5 anos e para a maioria $(87,9 \%)$ este apoio resume-se a um número que oscila entre 1-8 horas semanais.

A perceção que têm sobre quem presta ajuda em situações de emergência é muito positiva, ou seja têm a quem recorrer, assim como nas questões financeiras. Contudo há também quem se mostre preocupado com estas questões uma vez que se sente desapoiado.

A maioria $(54,5 \%)$ dos idosos inquiridos perceciona integrar famílias moderadamente funcionais, seguindo-se as altamente funcionais e por fim aquelas que acham ter disfunções acentuadas.

Relativamente ao investimento pessoal os dados mostram uma distribuição equitativa, uma vez que $39,4 \%$ perceciona o seu investimento como elevado , 33,3\% entende-o como pequeno e o grupo mais reduzido $(27,3 \%)$ acha que o investimento pessoal foi moderado. Neste caso os homens tendem a avaliar o investimento de uma forma mais positiva do que as mulheres.

A satisfação com a vida encontrada nos nossos participantes é de nível baixo para o maior grupo percentual (45,5\%), elevada para 36,3\%, e para $18,2 \%$ a satisfação é do tipo moderado. Também nesta variável encontramos visões mais positivas nos indivíduos do sexo masculino do que no sexo feminino.

As variáveis sociodemográficas e psicossociais incluídas no estudo, são independentes do grau de satisfação com a vida destes idosos, dada a não existência de relações significativas.

Envelhecer bem é um desejo de todos e portanto uma condição a ser alcançada, se a pessoa mantiver um baixo risco de doença, um 
funcionamento físico e mental elevado e também um compromisso ativo de investimento e satisfação com a vida.

Assim torna-se importante que se dê prioridade ao envelhecimento ativo nas suas várias dimensões (social, saúde, trabalho, habitação, cultura, lazer), e ao combate à pobreza e exclusão social das pessoas idosas. É importante que as pessoas idosas tenham uma participação ativa na sociedade, que se reconheça a sua heterogeneidade, mobilizando medidas específicas para os grupos mais vulneráveis nesta população.

\section{REFERÊNCIAS BIBLIOGRÁFICAS}

Agostinho, M., \& Rebelo, L. (1988). Família: Do conceito aos meios de avaliação. Revista Portuguesa Clinica Geral, 32, 6-17.

Alves, V. C. P. (2008). Stress e qualidade de vida em grupos de idosos: análise e comparação (Dissertação de mestrado, Pontifícia Universidade de Campinas). Acedido em http://www.bibliotecadigital.puc-campinas.edu.br/tde_arquivos/6/TDE-2008-0327T073234Z-1429/Publico/VIVIAN\%20PACOLA\%20ALVES.pdf

Andrade, A., \& Martins, R. (2011). Funcionalidade familiar e qualidade de vida dos idosos. Millenium, 40, 185-199. Acedido em http://www.ipv.pt/millenium/Millenium40/13.pdf

Antunes, A. P. F. (2010). Adequação da oferta de serviços de saúde e de apoio face às necessidades sentidas da população idosa do concelho de Constância (dissertação de mestrado, Universidade de Coimbra). Acedido em https://estudogeral.sib.uc.pt/handle/10316/14455

Capucha, L. (2005). Envelhecimento e políticas sociais: Novos desafios aos sistemas de proteção contra o "Risco de Velhice": Que risco? Acedido em http://ler.letras.up.pt/uploads/ficheiros/3736.pdf

Cerqueira M. M. (2010). Imagens do envelhecimento e da velhice (Tese de doutoramento, Universidade de Aveiro). Acedido em http://ria.ua.pt/bitstream/10773/6477/1/tese_margarida.cerqueira_out2010.pdf

Cruz, M. H. L. (2010). A influência da prática regular de exercício físico na percepção da qualidade de vida de idosos do género feminino (Dissertação de mestrado, universidade de Coimbra). Acedido em https://estudogeral.sib.uc.pt/bitstream/10316/12696/1/HC_sum\%C3\%A1rio\%20e \%20introdu\%C3\%A7\%C3\%A3o09.pdf

Fernandes, A. A. (2008). Questões demográficas: Demografia e sociologia da população. Lisboa: Edições Colibri.

Fortin, M. F. (2009). Fundamentos e etapas do processo de investigação. Loures: Lusociência.

Gonçalves, C. (2004). Pobreza e exclusão social nas famílias com idosos em Portugal, Revista de Estudos Demográficos, 35, 143-169. Acedido 
em:http://censos.ine.pt/xportal/xmain?xpid=CENSOS\&xpgid=ine_ce nsos_estudo_det\&menuBOUI=13707294\&contexto=es\&ESTUDOSe st_boui $=106284 \&$ ESTUDOSmodo $=2 \&$ selTab $=$ tab 1

Imaginário, C. (2004). O idoso dependente em contexto familiar. Coimbra: Formasau.

Joia, L. C., Ruiz, T., \& Donalisio, M. R. (2007). Condições associadas ao grau de satisfação com a vida entre a população de idosos. Revista de Saúde Pública, 41(1), 131-138. Acedido em http://www.scielo.br/pdf/rsp/v41n1/19.pdf

Martins, A. M. O., \& Carvalho, C. I. (2008). No crepúsculo da vida: Um olhar sentido sobre a vida conjugal. Revista de Ciències de l'Éducació, 1, 319-328. Acedido em http://pedagogia.fcep.urv.cat/revistaut/revistes/juny09/miscelania_article10.pdf

Martins, R. M. L. (2006). Envelhecimento e políticas sociais: O idoso na sociedade contemporânea. Millenium, 32, 126-140.

Martins, R. M. L., Santo, A. C. A. (2008). Ser idoso hoje. Millenium, 35, 69- 76.

Melo, C. A. D. (2009). As contribuições da psicanálise para a compreensão da posição feminina. Acedido em http://www.psicologia.pt/artigos/textos/TL0205.pdf

Mortágua, S. C. M. (2011). Relatório e contas de gerência de 2010 e parecer do Conselho Fiscal. Acedido em http://www.misericordiamortagua.pt/img/relatorio_act2010.pdf

Neri, A. L. (2001). Desenvolvimento e envelhecimento: Perspectivas biológicas, psicológicas e sociológicas. Campinas: Papiros.

Oliveira, B. (2010). Psicologia do envelhecimento e do idoso (4a ed.). Porto: Livpsic.

Paúl, M. C., Fonseca, A. M., Martin, I., \& Amado, J. (2005). Satisfação e qualidade de vida em idosos portugueses. In C. Paúl \& A. M. Fonseca (Coords.), Envelhecer em Portugal (pp. 75-108). Lisboa: Climepsi Editores.

Resende, M. C., Cunha, C. P. B., \& Sousa, A. P. S. S. J. (2007). Rede de relações sociais e satisfação com a vida de adultos e idosos. Ciências \& Cognição, 10, 164-177. Acedido em http://cienciasecognicao.org/pdf/v10/m317139.pdf

Ribeirinho, O. (2005). Quando o cuidador é um homem: Envelhecimento e orientação para o cuidado. In C. Paúl, \& A. M. Fonseca (Coords.), Envelhecer em Portugal: Psicologia, saúde e prestação de cuidados (pp. 231-254). Lisboa: Climepsi.

Santos, A. A., \& Pavarini, S. C. I. (2011). Funcionalidade familiar de idosos com alterações cognitivas em diferentes contextos de 
vulnerabilidade social. Revista Eletrónica de Enfermagem, 13(2), 361367. Acedido em http://www.fen.ufg.br/revista/v13/n2/v13n2a24.htm

Sequeira, C. (2010). Cuidar de idosos com dependência física e mental. Lisboa: Lidel.

Silva, J. V. (2009). Saúde do idoso: Processo de envelhecimento sob múltiplos aspectos. São Paulo: Iátria.

Silva, P. N. (2009). Adaptação à reforma e satisfação com a vida: A importância da actividade e dos papéis sociais na realidade europeia (Dissertação de mestrado, Instituto Universitário de Lisboa). Acedido em https://repositorio.iscte-iul.pt/handle/10071/1879

Smilkstein G. (1978). The family APGAR a proposal for a family function test and its use by physicians. Journal of Family Practice, 6(6), 1231-1239.

Teixeira, L. M. F. (2010). Solidão e qualidade de vida em idosos: Um estudo avaliativo exploratório e implementação: Piloto de um programa de intervenção (Dissertação de mestrado, Universidade de Lisboa). Acedido em http://repositorio.ul.pt/handle/10451/2608

Tonarelli, L. (2010). Life satisfaction in older people: Fostering happiness and contentment with life in elderly. Journal of Gerontological Nursing, 36(3). 